\title{
DEFINING GLOBAL CRETACEOUS EVENTS BY QUANTITATIVE STRATIGRAPHIC TECHNIQUES
}

SCOTT, R. W., Precision Stratigraphy Associates, 3734 S. Darlington, Tulsa, OK 74135, U.S.A.; FOUKE, B. W., and NEDERBRAGT, A. J., Free University of Amsterdam, De Boelelaan 1085, 1081 HV Amsterdam, The Netherlands.

The accurate and precise dating of geological events has been an important goal of stratigraphers since the advent of radiometric techniques and the first radiometric time scale in 1927. More recent time scales measure biotic and transgressive-regressive events and episodes very precisely by interpolation techniques. However, the subsequent correlation of these events with a new stratigraphic section is accomplished by subjective and inaccurate techniques.

Graphic correlation is a numerical correlation technique that is simple to apply and gives precise and reproducible correlations. Graphic correlation is based on an integrated data base of fossil tops and bases and other geologic events. The technique creates hypotheses of correlation that make no assumptions about the completeness of the each fossil range.

A composite standard data base from the Aptian through the Turonian has been constructed using $\mathbf{2 5}$ geologic sections in the Tethyan Realm. More than 800 bioevents of ammonites, inoceramids, planktic foraminifers, selected benthic forams, nannofossils, dinoflagellates, and selected spores and pollen have been integrated with nearly 100 depositional and geochemical events. Among these fossils are many of the zonal indicators. The stadial boundaries are defined by key taxa in generally accepted reference sections in France, Tunisia and Texas. The scale is calibrated to the Harland time scale.

Several scales of depositional cycles defined by sequence stratigraphic criteria have been correlated into this Mid-Cretaceous composite standard data base. Albian cycles average $1.74 \mathrm{~m} . \mathrm{y}$. in duration and Cenomanian cycles average 1.07 m.y. Turonian cycles average 0.59 m.y. long. Anoxic events were defined by the inflection points on $\delta \mathrm{C}^{13}$ excursions. The Aptian and Albian events, OAE 1a and b, were 350 k.y. long and the latest Cenomanian, OAE 2, was 600 m.y. in duration.

In northeastern Italy a Cretaceous basinal succession of red, green and gray limestone and shale is well exposed in the Cismon reference section, which is about $65 \mathrm{~km}$ west of the Friuli Platform platform. The Aptian-Albian contact is a disconformity with an $11 \mathrm{~m} . \mathrm{y}$. hiatus. The abundance peaks of planktic forams seem to correspond with marine productivity events above this break and within the Cenomanian interval. Graphic correlation projects the base of the Cenomanian $2 \mathrm{~m}$ below the base of Rotalipora brotzeni and a three-fold decrease in the rate of sediment accumulation from 0.78 to 0.26 $\mathrm{cm} / \mathrm{k} . \mathrm{y}$. 